\title{
Condensation Heat Transfer on Patterned Surfaces
}

\author{
Abhra Chatterjee, Melanie M. Derby, Yoav Peles, Michael K. Jensen \\ Department of Mechanical, Aerospace, and Nuclear Engineering \\ Rensselaer Polytechnic Institute \\ Troy, NY 12180
}

\begin{abstract}
An experimental study of condensation heat transfer was carried out on a $25.4 \mathrm{~mm}$ diameter surface using steam as the condensing fluid. Three surface conditions were studied: hydrophilic, hydrophobic, and a surface with patterns of distinct hydrophilic and hydrophobic regions. The effects of inlet vapor velocity, mass flux, and hydraulic diameter on the heat transfer coefficients were investigated. The inlet vapor velocity was varied from about $0.05 \mathrm{~m} / \mathrm{s}$ to about $5 \mathrm{~m} / \mathrm{s}$ and the hydraulic diameter was varied from $4.5 \mathrm{~mm}$ to $32.5 \mathrm{~mm}$. Depending on the surface condition, the heat transfer coefficients showed different responses to the varying parameters of the experiments. For the hydrophilic surface, the heat transfer coefficient was observed to be up to 2.5 times lower than that for the hydrophobic surface with all other parameters unaltered. On the other hand, the surface with a pattern of distinct hydrophobic and hydrophilic regions showed heat transfer coefficients that were higher than that of the hydrophilic surface and lower than that of the hydrophobic surface. In both the patterned and the hydrophobic surfaces, the heat transfer coefficient was observed to increase significantly with mass flux, while for the
\end{abstract}

November 26, $2012 \quad$ Chatterjee 
hydrophilic surface, the heat transfer coefficient was observed to be affected much less by the mass flux. In all cases, the heat transfer coefficients increased with increasing heat flux and decreased with increasing wall sub-cooling. The effect of average quality of the steam showed little effect on the heat transfer coefficients.

Keywords Condensation; vapor space; pattern; hydrophilic; hydrophobic; mass flux

\section{Introduction}

Condensation is an important research area because of its wide range of applications like in the power generation industry, distillation industry and in industrial cooling operations both at macro and micro scales. Likewise, enhancement of heat transfer coefficients for condensation is an active area of research. Conventionally, some of the methods employed to enhance condensation heat transfer coefficient are chemical treatment of the condensation surface, exploiting surface texture to drain the condensate, and adding chemicals to the vapor to affect its interaction with the surface [1-3]. The choice of the methods involved to enhance heat transfer depends on the conditions in which condensation takes place.

Heat transfer coefficients due to condensation can vary significantly depending on the operating conditions [4]. When the vapor velocities are high and interfacial shear stress on the condensate is influenced by the flowing vapor, condensation can be classified as flow condensation or convective condensation. On the other hand, for low vapor velocities, when interfacial stress is small or non-existent, surface tension effects of the condensate become important and condensation is classified as vapor space condensation [4]. However, the 
parameters that set flow condensation apart from vapor space condensation are not clearly defined.

In vapor space condensation the interaction of the condensate with the condensation surface is an important factor controlling the heat transfer process [5]. If the condensed fluid quickly coalesces, forms a thin film, and wets the entire surface, filmwise condensation $(F W C)$ is said to have taken place [6]. This is a result of high surface energy of the condensation surface and is observed on surfaces which are hydrophilic. On the other hand, dropwise condensation (DWC) occurs in the form of liquid droplets on surfaces which are not wetted by the liquid and is a result of low surface energy of the condensation surface; such surfaces are said to be hydrophobic. DWC is characterized by higher contact angle of the droplets when compared to that of FWC [6].

For $F W C$, the effects of acceleration due to gravity and shear at the interface of the condensate and the vapor have been reported [7]. Analytical equations for heat transfer coefficients have been developed for condensation on a flat plate where there is either only the force of gravity or there is only shear forces (Equations 1 and 2); when both forces are present, the heat transfer coefficient can be estimated by combining the heat transfer coefficients from the individual equations using Equation 3 [7].

$$
\begin{gathered}
h_{g v}=1.1 \operatorname{Re}_{\Gamma}^{-1 / 3} k_{l}\left[\frac{\rho_{l}\left(\rho_{l}-\rho_{v}\right) g}{\mu_{l}^{2}}\right]^{1 / 3} \\
h_{s v}=1.1 \operatorname{Re}_{\Gamma}^{-1 / 2} k_{l}\left[\frac{\rho_{l}\left(\rho_{l}-\rho_{v}\right) g}{\mu_{l}^{2}}\right]^{1 / 3}\left(\tau_{i}^{+}\right)^{1 / 2} \\
h^{2}=h_{g v}^{2}+h_{s v}^{2}
\end{gathered}
$$


where, $h_{g v}$ is the heat transfer coefficient only due to gravity, $h_{s v}$ is the heat transfer coefficient due to shear force on the interface of the condensate and the vapor, $h$ is the heat transfer coefficient due to the effects of both gravity and shear forces, $\operatorname{Re}_{\Gamma}$ is the Reynolds number based on the condensate flow rate, $k_{l}$ is the thermal conductivity of the condensate, $\rho_{l}$ is the density of the condensate, $\rho_{v}$ is the density of the vapor, $\mu_{v}$ is the viscosity of the vapor, $g$ is the acceleration due to gravity, and $\tau_{i}^{+}$is the non-dimensional shear stress at the interface of the condensate and the vapor.

Mobility of the condensate on the condensation surface also greatly affects the heat transfer. The diameter at which a droplet slides down a vertical condensation surface due to the effect of external forces is called the departure diameter; this typically occurs when the droplet is large. When a condensation surface is washed by higher frequency of falling droplets the heat transfer coefficient increases. McCormick and Baer [8] reported that droplet growth and dynamics significantly affected the heat transfer performance. Thus, droplet mobility becomes an important factor in condensation heat transfer. When a large drop moves away from the point of incipience, the moving drop washes away smaller drops in its path due to the cohesive nature of the liquid [9]. In $D W C$, droplets are readily able to be removed from their nucleation sites [10] and, hence, for $D W C$ heat transfer coefficients have been observed to be up to an order of magnitude higher than that of FWC [6].

While it is accepted that $D W C$, which is observed in hydrophobic surfaces, results in high heat transfer coefficients [5], it has been observed that the nucleation rate is larger with hydrophilic surfaces [11]. This is due to the fact that the nucleation rate depends on the free energy barrier of the condensation surface, which in turn is a strong function of surface 
wettability [4]. The relationship between the nucleation rate and the free energy barrier can be expressed as [11]:

$$
J=J_{0} e^{-\Delta G / K T}
$$

where, $J$ is the nucleation rate, $J_{0}$ is the Kinetic constant, $\Delta \mathrm{G}$ is the free energy barrier, $K$ is the Boltzmann constant, $T$ is the absolute temperature.

Since, hydrophilic surfaces have a smaller free energy barrier when compared to hydrophobic surfaces, they have higher rates of nucleation, as can be concluded from equation (4) and discussed by Varanasi et al. [11]. Thus, it is inferred that a while hydrophobic surface is necessary for $D W C$ and high heat transfer coefficient, a hydrophilic surface is necessary to achieve high condensation rate.

While hydrophobic surfaces are associated with higher heat transfer coefficients when compared to that with hydrophilic surfaces, using a pattern of distinct hydrophobic and hydrophilic regions on the condensation surface may or may not enhance heat transfer coefficient. A study by Leu et al. [12] shows that some condensation surfaces with specific patterns of distinct hydrophobic and hydrophilic regions can result in higher heat flux than that of completely hydrophobic surfaces, while other patterns can result in lower heat flux when compared to completely hydrophilic surfaces.

Previous studies on condensation heat transfer on hydrophilic surfaces, hydrophobic surfaces, and surfaces with distinct patterns of hydrophilic and hydrophobic regions have been conducted. However, the effect of vapor velocity and dimensions of the flow chamber have not been adequately investigated, especially in the case of vapor space. Hence, the present study 
investigates the effect of vapor velocity and the dimension of the condensation chamber for surfaces that are hydrophilic, and hydrophobic. For surfaces with patterns of distinct hydrophilic and hydrophobic regions, certain patterned surfaces have the potential to enhance the heat transfer coefficient for condnesation, others may not be able to do so [12]. Hence, a surface with patterns of distinct hydrophobic and hydrophilic regions has also been investigated.

\section{Experimental Apparatus and Procedure}

A chamber with a variable hydraulic diameter with an open steam loop was constructed as shown in Fig. 1(a). The loop consisted of a steam supply line at $445 \mathrm{kPa}$, a filter, a steam separator, a valve, an immersion heater, a test section, a heat exchanger, a flow meter and a drain. The entire flow loop was insulated to minimize heat loss. After the steam exits the test section, a heat exchanger was employed to completely condense the steam to allow steam mass flow rate measurement using a rotameter.

The test section consisted of a vapor chamber, a piston, a vertical condensation surface, the test section, and a visualization window (Figure 1(b)). The vapor chamber was constructed from a translucent polysulphone plastic, and the piston was constructed from a glass-filled polycarbonate, both with good insulation properties. The vapor chamber was $124 \mathrm{~mm}$ long and $45.7 \mathrm{~mm}$ wide, and the depth of the chamber could be varied between $2 \mathrm{~mm}$ to $25 \mathrm{~mm}$.

The condensation surface was comprised of a $25.4 \mathrm{~mm}$ diameter and $7 \mathrm{~mm}$ thick cylindrical coupon made of oxygen-free copper (Alloy 101). Experiments were performed on three types of surfaces:

1. Completely hydrophilic, i.e., bare copper surface (contact angle for water $\approx 60^{\circ}$ ) 
2. Completely hydrophobic, i.e., copper surface coated with Teflon $\mathrm{AF}^{\mathrm{TM}}, 200 \mathrm{~nm}$ thick (contact angle for water $\approx 115^{\circ}$ )

3. Surface with a pattern of distinct hydrophilic and hydrophobic regions.

Two bare copper surfaces with different surface roughnesses served as the hydrophilic surface. The two surfaces had an average roughness, i.e., $\mathrm{R}_{\mathrm{a}}$ of $0.02 \mu \mathrm{m}$ and $0.1 \mu \mathrm{m}$.

For obtaining patterns of distinct hydrophilic and hydrophobic regions, the copper was first completely coated with Teflon $\mathrm{AF}^{\mathrm{TM}}$ and then the coating was selectively masked and etched away. The method of plasma etching was employed to expose the hydrophilic bare copper from the Teflon $\mathrm{AF}^{\mathrm{TM}}$ coated surface. The surface roughness of the completely hydrophobic surface was $\mathrm{R}_{\mathrm{a}} \approx 0.04 \mu \mathrm{m}$.

The patterned surface, on which condensation experiments were performed, was comprised of $25 \%$ hydrophilic region and $75 \%$ hydrophobic region by area, as shown in Fig. 2. The hydrophilic regions were circular islands of $1.5 \mathrm{~mm}$ diameter.

One of the two flat sides of the cylindrical coupon served as the condensation surface and the other flat side was soldered to a copper block, which was cooled at the opposite end through a bath circulator, which maintained the cooling water temperature at a specified value. Thermocouples were attached along the axis of the copper block to obtain the heat flux, which allowed calculation of the heat transfer coefficient.

A needle valve located upstream of the test section was used to control the mass flow rate of the vapor into the test section. By varying the mass flow rate of the steam and the piston position, the mass flux was varied between $0.03 \mathrm{~kg} / \mathrm{m}^{2} \mathrm{~s}$ and about $6 \mathrm{~kg} / \mathrm{m}^{2} \mathrm{~s}$. The steam was let into the condensation chamber from the top. The vapor was then allowed to pass through the test section. 
Finally the vapor/liquid mixture exited from the bottom of the vapor chamber. The condensation chamber was maintained slightly above atmospheric pressure.

To obtain data, the cooling water bath circulator was first set to a temperature of $30^{\circ} \mathrm{C}$, so that a constant temperature was maintained at the cooling end of the copper block. The mass flow rate of the cooling water was about $0.2 \mathrm{~kg} / \mathrm{s}$ and the change in the temperature of the cooling water was less than $0.3^{\circ} \mathrm{C}$. Followed by the bath circulator, the steam supply was turned on and the valve upstream of the test section was adjusted to obtain the desired mass flow. The immersion heater was then switched on and the heating power was adjusted with the help of a variable power supply to obtain a stable and small superheat of approximately of $0.5^{\circ} \mathrm{C}$ before the steam entered the test section. The superheat was necessary to obtain the exact state at which the vapor entered the test section and to calculate the quality of the steam leaving the test section through a heat balance. After steady state was reached, the experimental data of temperature and pressure were recorded using a computer controlled data acquisition system of National Instruments and LabVIEW software. The flow parameter was then altered and the entire procedure was repeated. The same steps were carried out for several positions of the piston with the hydraulic diameter of the vapor space ranging between $4.5 \mathrm{~mm}$ and $32.5 \mathrm{~mm}$. The data was reduced and analyzed with the help of computer programs written in Engineering Equations Solver (EES) software. Visualization of the mode of interaction of the condensates on the condensation surface was done with a Nikon digital camera.

\section{Data Reduction}


Temperature, pressure, and mass flow rate of the vapor were directly measured and were used to calculate the heat flux, heat transfer coefficient, wall sub-cooling, and the exit quality of the fluid.

Five equally spaced thermocouples were used to obtain the temperature along the axis of the copper block. A linear curve fit of the temperature and the location of the thermocouples gave the temperature gradient along the axis of the copper block. Assuming 1-D heat transfer, Fourier's law was then used to calculate the heat flux through the test section:

$$
Q^{\prime \prime}=-k_{c u} d T / d y
$$

where, $Q$ " is the heat flux through the condensation surface, $k_{c u}$ is the thermal conductivity of oxygen-free copper and $d T / d y$ is the temperature gradient along the copper block.

Another thermocouple fixed to the copper coupon and close to the condensation surface was used to calculate the wall temperature using the following equation:

$$
T_{w}=T_{1}+Q^{\prime \prime} \Delta y / k_{c u}
$$

where, $T_{w}$ is the wall temperature, $T_{1}$ is the temperature read by the thermocouple closest to the condensation surface, and $\Delta y$ is the distance between the thermocouple and the condensation surface.

The heat transfer coefficient was calculated using the following equation:

$$
h=Q^{\prime \prime} /\left(T_{\text {sat }}-T_{w}\right)
$$


where, $h$ is the heat transfer coefficient and $T_{\text {sat }}$ is the saturation temperature of the vapor.

Since the vapor entered the test section with a small superheat, the thermal state of the entering steam was known from the temperature and pressure measurement. Applying a heat balance to the test section, the exit quality could be calculated:

$$
x=\frac{i_{i}-i_{f}-Q " A / \dot{m}}{i_{f g}}
$$

where, $x$ is the quality of the vapor at the exit of the test section, $\dot{m}$ is the mass flow rate of the vapor, $A$ is the surface area of the condensation surface, $i_{i}$ is the specific enthalpy of the steam at the inlet of the test section, $i_{f}$ is the specific enthalpy of the saturated liquid at the given pressure and $i_{f g}$ is the specific enthalpy of vaporization of water at the given temperature.

The wall subcooling has been defined as the difference between the temperature of the condensation surface and that of the vapor which is expressed in the following equation:

$$
\Delta T=T_{\text {sat }}-T_{w}
$$

The temperature and pressure was measured with an accuracy of $\pm 0.1^{\circ} \mathrm{C}$ and $5 \mathrm{kPa}$, while the steam flow rate was measured with an accuracy of $0.5 \mathrm{~mL} / \mathrm{min}$. The uncertainty analysis was carried out using the error-ratio and standard deviation method adapted by Kedzierski and 
Worthington [13]. The typical uncertainties in the calculated heat transfer coefficients were estimated to be less than $\pm 6 \%$.

\section{Results and Discussion}

Experiments on vapor condensation have been conducted on a vertical test section with the condensation surface being completely hydrophilic (bare copper), completely hydrophobic (copper coated with Teflon $\mathrm{AF}^{\mathrm{TM}}$ ), and a surface with a pattern of distinct hydrophobic and hydrophilic regions. The experimental parameters were the same for all the three surfaces. The inlet vapor velocity was varied from about $0.02 \mathrm{~m} / \mathrm{s}$ to about $5.5 \mathrm{~m} / \mathrm{s}$, and the hydraulic diameter of the vapor chamber was varied from about $4.5 \mathrm{~mm}$ to about $32.5 \mathrm{~mm}$. Experimental results with respect to heat transfer coefficient and heat flux have been observed to be different for the three different surfaces. The cooling water temperature was maintained at a constant value of 30 ${ }^{\circ} \mathrm{C}$. Experiments with higher cooling water temperature did not yield much different results.

\section{Completely hydrophilic surface}

The heat transfer coefficients observed for the two completely hydrophilic surfaces with different surface roughness $\left(\mathrm{R}_{\mathrm{a}} \approx 0.1 \mu \mathrm{m}\right.$ and $\left.\mathrm{R}_{\mathrm{a}} \approx 0.02 \mu \mathrm{m}\right)$ were very similar as seen in Fig. 3 . For both the surfaces, heat transfer coefficients were between $9800 \mathrm{~W} / \mathrm{m}^{2} \mathrm{~K}$ to about $12500 \mathrm{~W} / \mathrm{m}^{2} \mathrm{~K}$, for the range of inlet vapor velocities and hydraulic diameters in the experiments performed. Figure 3 shows that the heat transfer coefficients for the two surfaces with different surface roughnesses are within the uncertainty limits of each other, which is about $5 \%$. 
Unless otherwise mentioned, hydrophilic surface henceforth would imply hydrophilic surface with surface roughness of $\mathrm{R}_{\mathrm{a}} \approx 0.1 \mu \mathrm{m}$. Although an increase in the heat transfer coefficient with increasing inlet vapor velocity was observed, the hydraulic diameter of the vapor chamber did not have a significant effect on the heat transfer coefficient as shown in Fig. 4.

A comparison of theoretical analysis of heat transfer for filmwise condensation (equations 13) and the experimental results obtained is presented in Fig. 5. The plot shows that the forces acting on the condensates in the present experiments are dominated by gravity and the interfacial shear forces have little effect.

A film of liquid condensate was observed to cover the entire condensation surface as shown in Fig. 6. Thus the mode of interaction of the condensate with the condensation surface was observed to be that of filmwise condensation (FWC). FWC has been observed to result in relatively low heat transfer coefficient when compared to DWC [6], and the present set of experiments is in agreement with previous studies. . The film covering the entire surface prevented direct contact between the vapor and the condensation surface thereby reducing the heat transfer coefficient.

The heat transfer coefficient was observed to increase with increasing heat flux and decrease with increasing wall sub-cooling as shown in Fig. 7 and Fig. 8.

\section{Completely hydrophobic surface}

The completely hydrophobic condensation surface (i.e., the copper substrate coated with Teflon $\mathrm{AF}^{\mathrm{TM}}$ ) had heat transfer coefficients of up to about $32000 \mathrm{~W} / \mathrm{m}^{2} \mathrm{~K}$, for the same range of inlet vapor velocities and hydraulic diameters as that in the case of completely hydrophilic surface which was approximately 2.5 times larger than the highest heat transfer coefficient observed with the completely hydrophilic surface. This agrees well with the observation of 
higher heat transfer coefficients for hydrophobic surface when compared to hydrophilic surfaces by Dongchang et al [6], although they reported a much higher increase in the heat transfer coefficient.

A substantial increase in the heat transfer coefficient with increasing inlet vapor velocity was observed (Fig. 9) at lower inlet vapor velocities but at higher vapor velocities, the heat transfer coefficients were insensitive to velocity. Unlike in the case of completely hydrophilic surface, the hydraulic diameter showed an effect of the inlet vapor velocity at which the heat transfer coefficient became independent of vapor velocity. The leveling off of the heat transfer coefficient was reached at lower mass flow rates for smaller hydraulic diameters when compared to that of higher hydraulic diameters.

The condensation process on the surface was observed to be a combination of FWC and $D W C$. DWC was observed mainly towards the periphery of the condensation surface, and FWC was observed around the center of the surface as also observed by Baojin [5]. A steady stream or rivulet of condensate was also observed toward the geometric center of the condensation surface as shown in Fig. 10. Droplets were seen to nucleate, grow, coalesce and depart from the nucleation sites. In regions close to the streams, drops were drawn into the rivulets before reaching the departure diameter, similar to what was observed by Baojin [5]. The droplets were large and slow in departing from the nucleation sites at lower vapor velocities when compared to that at higher vapor velocities. This probably resulted in higher heat transfer rates that were observed at higher vapor velocities when compared to that of lower velocities. These results concur with the results of Leach et al. [14] and Rose and Glicksman [15] who also observed that for smaller droplets the heat transfer rate was more than for larger droplets. At higher vapor velocities of the vapor, the droplets departed from their nucleation sites at higher frequencies thus adding to the enhancement of heat transfer. Also, at higher vapor velocities, the size of the 
departing droplets was not observed to vary much with increasing velocity, and as a result the heat transfer coefficient changed little with vapor velocity at higher velocities.

The typical time that the condensate droplets took between nucleation and departing was about $3 \mathrm{~s}$ at an inlet vapor velocity of $5 \mathrm{~m} / \mathrm{s}$ (fig. 11). The droplets formed all over the hydrophobic surface, which was in contrast with the patterned surface where the droplets predominantly formed on hydrophilic regions. The steady flow of the condensate, whether in the form of droplets or rivulets contributed to the high heat transfer coefficient of the completely hydrophobic surface.

Similar to the completely hydrophilic surface, the heat transfer coefficients increased with increasing heat flux and decreased with increasing wall sub-cooling as shown in Figs. 12, 13.

\section{$\underline{\text { Patterned surface }}$}

The highest heat transfer coefficients on the patterned surface were lower than those of the completely hydrophobic surface and higher than those of the completely hydrophilic surface as shown in Fig. 14. The hydraulic diameter of the vapor chamber showed an effect on the heat transfer coefficients, which was similar to that of completely hydrophobic surface.

Visualization of the condensation modes showed that the hydrophilic regions were covered by bigger droplets while the hydrophobic region had relatively smaller droplets covering them, as shown in Fig. 15. This is because the hydrophilic surfaces have higher surface energies and show higher rates of condensation. This observation agrees well with the experiments conducted by Varanasi [11]. Unlike the case of completely hydrophobic surface, steady streams or rivulets of condensates were not observed. At lower vapor inlet velocities, it was observed that the droplets formed in the hydrophilic islands after growing to departure diameter were impeded by 
the neighboring hydrophobic region from moving vertically downward. However, this effect was much less pronounced at higher vapor velocities.

Similar to the completely hydrophobic surface, the droplets were seen to nucleate, grow, coalesce and depart from the nucleation sites, as shown in Fig 16. However, unlike the completely hydrophobic surface, no steady rivulets were observed, and the droplets were distributed evenly throughout the surface. This was because of the fact that the droplets preferentially formed on the hydrophilic islands which were distributed evenly on the surface.

Mccormick and Baer [8] observed that the condensate droplet size dynamics greatly affected the heat transfer coefficient. On the other hand, Grooten and Geld [16] reported that with higher frequency of droplet removal, the average size of droplets sticking onto the condensation surface decreases. The time between nucleation and departure of the droplet from the nucleation time was $12 \mathrm{~s}$ (fig. 16). Thus, the frequency with which the droplets departed from their respective condensation sites was observed to be lower for the patterned surface when compared to that of the completely hydrophobic surface, which also may have contributed to the lower heat transfer coefficient for the patterned surface when compared to that of the completely hydrophobic surface. The reason the frequency of departure of the droplets decreased can be attributed to the fact that the hydrophilic island were not connected to each other, and thus droplets had to cross the barrier of the water repelling hydrophobic region to coalesce and depart. Also, the due to the lower frequency of the droplet departure, the size of the droplets that could form on the condensation surface was also bigger.

Similar to the other two surfaces, heat transfer coefficients were observed to increase with increasing heat flux and decrease with increasing wall sub-cooling as shown in Figs. 17, 18. 
The heat transfer coefficients were the highest in for the completely hydrophobic surface (Fig. 19) followed by those of the patterned surface; the lowest heat transfer coefficients were observed for the completely hydrophilic surface. The variation in the heat transfer coefficients for different surfaces can be attributed to the different modes of interaction and mobility of the condensate at the condensation surface. The smaller diameter and higher frequency of the departing droplets on the completely hydrophobic surface when compared to those on the patterned surface resulted in higher heat transfer coefficients on the completely hydrophobic surface than on the patterned surface. The condensate film on the completely hydrophilic surface prevented direct contact between the condensation surface and the vapor resulting in the lowest heat transfer coefficient among all the surfaces.

The heat transfer coefficient as a function of the wall sub-cooling (Fig. 18) shows that all three surfaces collapse onto a single curve although the heat flux varied from one point to another.

\section{Conclusions}

An experimental parametric study on condensation was performed on three types of surfaces. The experimental parameters for all the three surfaces were kept the same. The following conclusions can be drawn from the experimental results:

- Gravity was the dominant force on the condensate. Shear forces on the vaporcondensate interface had little effect on the heat transfer coefficient.

- The effect of vapor velocity or mass flux on heat transfer coefficient was different for different surfaces. Heat transfer coefficients were the highest for the completely 
hydrophobic surface, followed by the patterned surface, and the completely hydrophilic surface.

- For the completely hydrophobic surface and the patterned surface, the vapor mass flow rate at which the heat transfer rate became insensitive to velocity, was lower for higher hydraulic diameter of the vapor chamber.

- The heat transfer coefficients were greatly influenced by the mode by which the condensates interacted with the condensation surface, with FWC resulting in lower heat transfer coefficient and DWC showing higher heat transfer coefficients.

- Smaller and faster moving condensate droplets resulted in higher heat transfer coefficients when compared to bigger and slower moving droplets.

- For the patterned surface, the hydrophilic regions attracted condensate droplets toward it from the hydrophobic regions and resulted in slower movement of condensate when compared to the completely hydrophobic surface.

\section{Acknowledgments}

The authors acknowledge the financial support of Office of Naval Research through a MURI grant. Grant Number N00014-07-1-0723 entitled “System-Level Approach for Multi-Phase, Nanotechnology-Enhanced Cooling of High-Power Microelectronic Systems.” Support and cooperation from Rensselaer Polytechnic Institute is also acknowledged.

\section{Nomenclature}


acceleration due to gravity

$h \quad$ heat transfer coefficient

$h_{g v} \quad$ transfer coefficient only due to gravity

$h_{s v} \quad$ heat transfer coefficient vapor-condensate interfacial shear

$i_{f} \quad$ specific enthalpy of saturated liquid

$i_{f g} \quad$ specific enthalpy of vaporization

specific enthalpy of inlet vapor

nucleation rate condensate

$J_{0} \quad$ kinetic constant of nucleation rate condensate

K

Boltzmann constant

$k_{c u}$

thermal conductivity of oxygen free copper

$k_{l} \quad$ thermal conductivity of the condensate

$\dot{m} \quad$ vapor mass flow rate

Q" heat flux

$\operatorname{Re}_{\Gamma} \quad$ Reynolds number based on the condensate flow rate

$d T / d y \quad$ heat temperature gradient along the copper cooling block

T absolute temperature

$T_{w} \quad$ calculated wall temperature

$T_{1} \quad$ temperature of the thermocouple closest to the condensation surface

$x$ steam quality

$y \quad$ distance of thermocouple 
Greek

$\mu_{l} \quad$ viscosity of the condensate

$\rho_{l} \quad$ density of the condensate

$\rho_{v} \quad$ density of the vapor

$\tau_{i}^{+} \quad$ non-dimensional shear stress at the interface of the condensate and the vapor

\section{References}

[1] C. A. Nash and J. W. Westwater, "A Study of Novel Surfaces for Dropwise Condensation," in Proceedings of the ASME.JSME Thermal Engineering Joint Conference, Honolulu, HI, 1987.

[2] S. Daniel, M. K. Chaudhury and J. C. Chen, "Fast Drop Movements Resulting from the Phase Change on Gradient Surface," Science, vol. 291, pp. 633-636, 2001.

[3] J. N. A. Morrison and J. Deans, "Augmentation of Steam Condensation Heat Transfer by Addition of Ammonia," International Journal of Heat and Mass Transfer, vol. 40, no. 4, p. 765-772, 1997.

[4] R. A. Sigsbee, Nucleation, New Yorker, 1969.

[5] Q. Baojin, Z. Li, X. Hong and S. Yan, "Experimental Study on Condensation Heat Transfer of Steam on Vertical Titanium Plates with Different Surface Energies," Experimental Thermal and Fluid Science, vol. 35, p. 211-218, 2011.

[6] Z. Dongchang, L. Zaiqi and L. J. Feng, "New Surface Materials for Dropwise Condensation," in Proceedings of the 8th Heat Transfer Conference, San Francisco, CA, 1986. 
[7] A. Faghri, Y. Zhang and J. Howell, Advanced Heat and Mass Transfer, Global Digital Press, 2010.

[8] J. L. McCormick and E. Baer, "On the Mechanism of Heat Transfer in Dropwise Condensation," Journal of Colloid Science, vol. 18, p. 208-216, 1963.

[9] C. Yamali and H. Merte, "A Theory of Dropwise Condensation at Large Subcooling Including the Effect of the Sweeping," Heat and Mass Transfer, vol. 38, no. 3, pp. 191202, 2001.

[10] Y. L. Lee, "The Enhancement of Dropwise Condensatoin by Wettability Modification of Solid Surface," International Communications in Heat and Mass Transfer, vol. 25, no. 8, pp. 1095-1103, 1998.

[11] K. K. Varanasi, M. Hsu, N. Bhate, W. Yang and T. Deng, "Spatial Control in the Heterogeneous Nucleation of Water," Applied Physics Letters, vol. 95, no. 9, pp. 094101-3, 2009.

[12] T. S. Leu, H. W. Lin and T. H. Wu, "Enhancement of Phase Change Heat Transfer by Using Surface Energy Patterning Techniques," Proceedings of the 1st IEEE International, Conference on Nano/Micro Engineered and Molecular Systems, pp. 994 - 998, 2006.

[13] M. A. Kedziersk and J. L. Worthington, "Design and Machining of Copper Specimens with Micro Holes for Accurate Heat Transfer Measurements," Experimental Heat Transfer, vol. 6, pp. 329-344, 1993.

[14] R. N. Leach, F. Stevens, S. C. Langford and J. T. Dicksinson, "Experiments and Simulations of Nucleate and Growth of Water Drops in a Cooling System," Langmuir, vol. 22, p. 8864-8872, 2006.

[15] J. W. Rose and L. R. Glicksman, "Dropwise Condensation—-the Distribution of Drop Sizes," 
International Journal of Heat and Mass Transfer, vol. 16, no. 2, p. 411-425, 1973.

[16] M. H. Grooten and C. W. Geld, "The importance of drainage in dropwise condensation from flowing air-steam mixtures," in Proceedings of the 14th International Heat Transfer Conference, 2010, Washington, DC.

\section{Figure Captions}

Figure 1. (a) Schematic of the loop; (b) Schematic of the test section.

Figure 2. Schematic of the patterned surface; hydrophilic islands are $1.5 \mathrm{~mm}$ in diameter and $25 \%$ of the surface area of the condensation surface.

Figure 3. Variation of heat transfer coefficient with inlet vapor velocity for two surfaces completely hydrophilic surface.

Figure 4. Variation of heat transfer coefficient with inlet vapor velocity for completely hydrophilic surface.

Figure 5. Comparison of theoretical heat transfer analyses and the experiments for completely hydrophilic surface.

Figure 6. A film is seen to cover the entire hydrophilic surface.

Figure 7. Variation of heat transfer coefficient with wall sub-cooling for completely hydrophilic surface.

Figure 8. Variation of heat transfer coefficient with heat flux for completely hydrophilic surface.

Figure 9. Variation of heat transfer coefficient with inlet vapor velocity for completely hydrophobic surface.

Figure 10. A combination of $D W C$ and $F W C$ is seen on the condensation surface. Steady streams or rivulets are also seen toward the geometric center of the condensation surface.

Figure 11. Droplets are seen to (a) nucleate, (b) grow, (c) coalesce, and (d) depart on the peripheral regions of the completely hydrophobic condensation surface, while rivulets are seen on the central region 
Figure 12. Variation of heat transfer coefficient with wall subcooling for completely hydrophobic surface.

Figure 13. Variation of heat transfer coefficient with heat flux for completely hydrophobic surface.

Figure 14. Variation of heat transfer coefficient with inlet vapor velocity for patterned surface.

Figure 15. Bigger droplets are seen over the hydrophilic regions when compared to that over hydrophobic region.

Figure 16. Droplets (a) nucleate, (b) grow, (c) coalesce and (d) depart on the patterned surface with hydrophilic island diameter $\approx 1.50 \mathrm{~mm}$

Figure 17. Variation of heat transfer coefficient with wall sub-cooling for completely for patterned surface.

Figure 18. Variation of heat transfer coefficient with heat flux for completely for patterned surface.

Figure 19. Comparison of the variation of heat transfer coefficient with inlet vapor velocity for completely hydrophobic, completely hydrophilic and patterned surface.

Figure 20. Comparison of the variation of heat transfer coefficient with wall sub-cooling for completely hydrophobic, completely hydrophilic and patterned surface. 
Figures

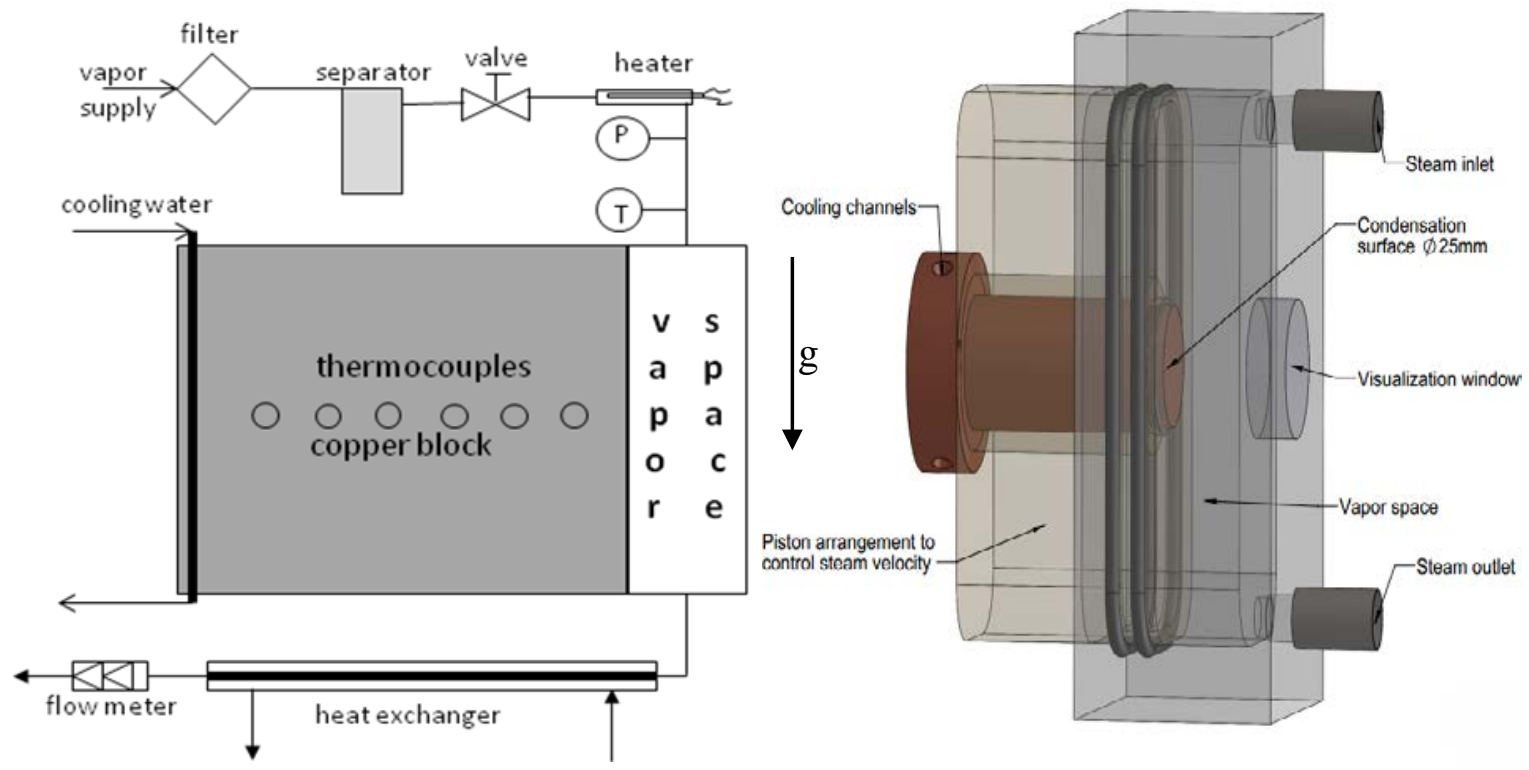

(a)

(b)

Figure 1. (a) Schematic of the loop; (b) Schematic of the test section. 
Hydrophobic region Hydrophilic islands

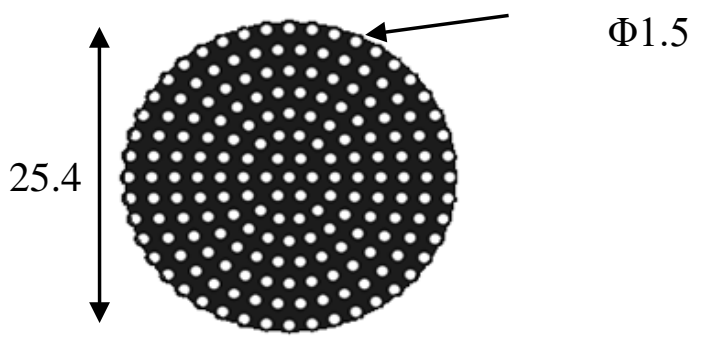

Figure 2. Schematic of the patterned surface; hydrophilic islands are $1.5 \mathrm{~mm}$ in diameter and $25 \%$ of the surface area of the condensation surface.

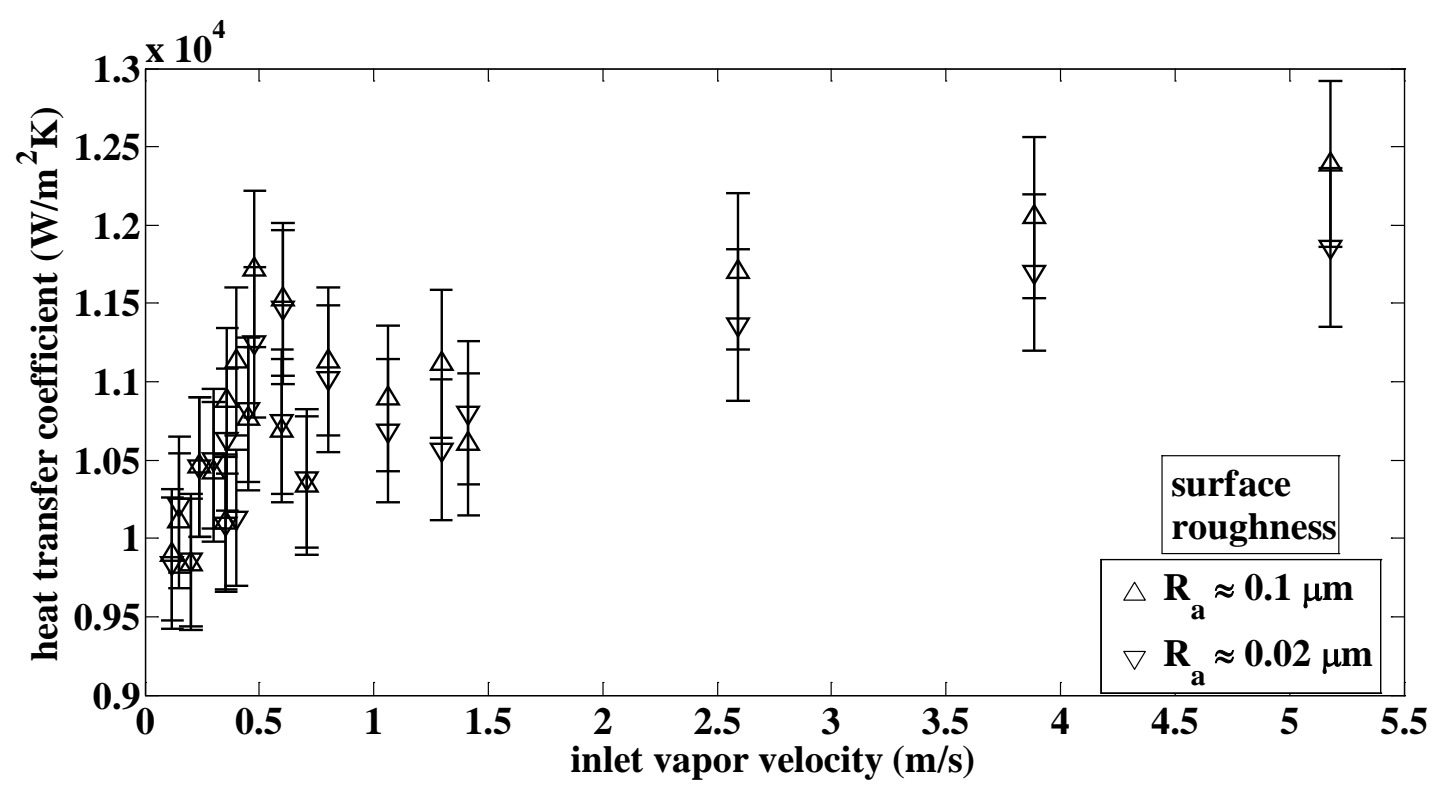

Figure 3. Variation of heat transfer coefficient with inlet vapor velocity for two surfaces completely hydrophilic surface. 
Condensation Heat Transfer on Patterned Surfaces

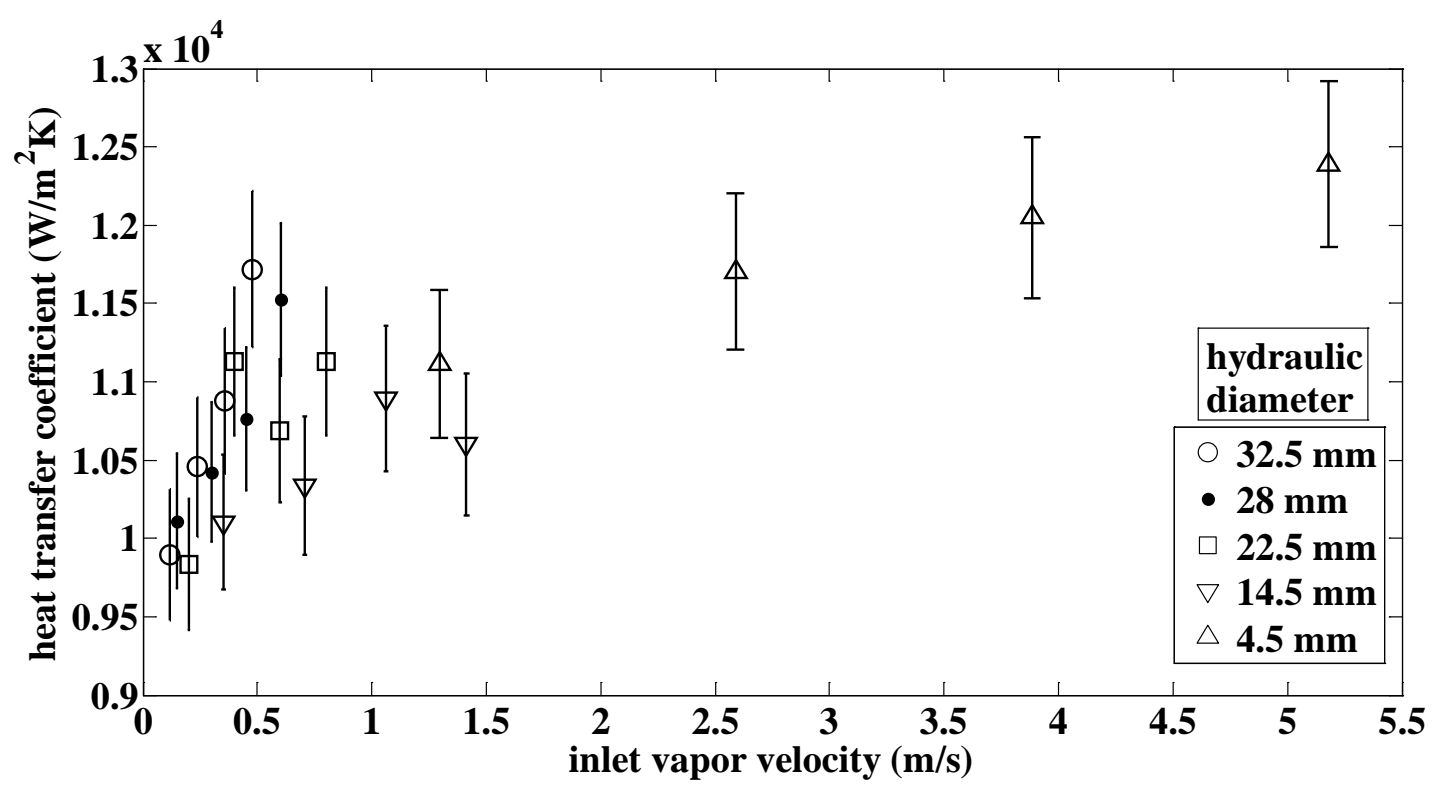

Figure 4. Variation of heat transfer coefficient with inlet vapor velocity for completely hydrophilic surface.

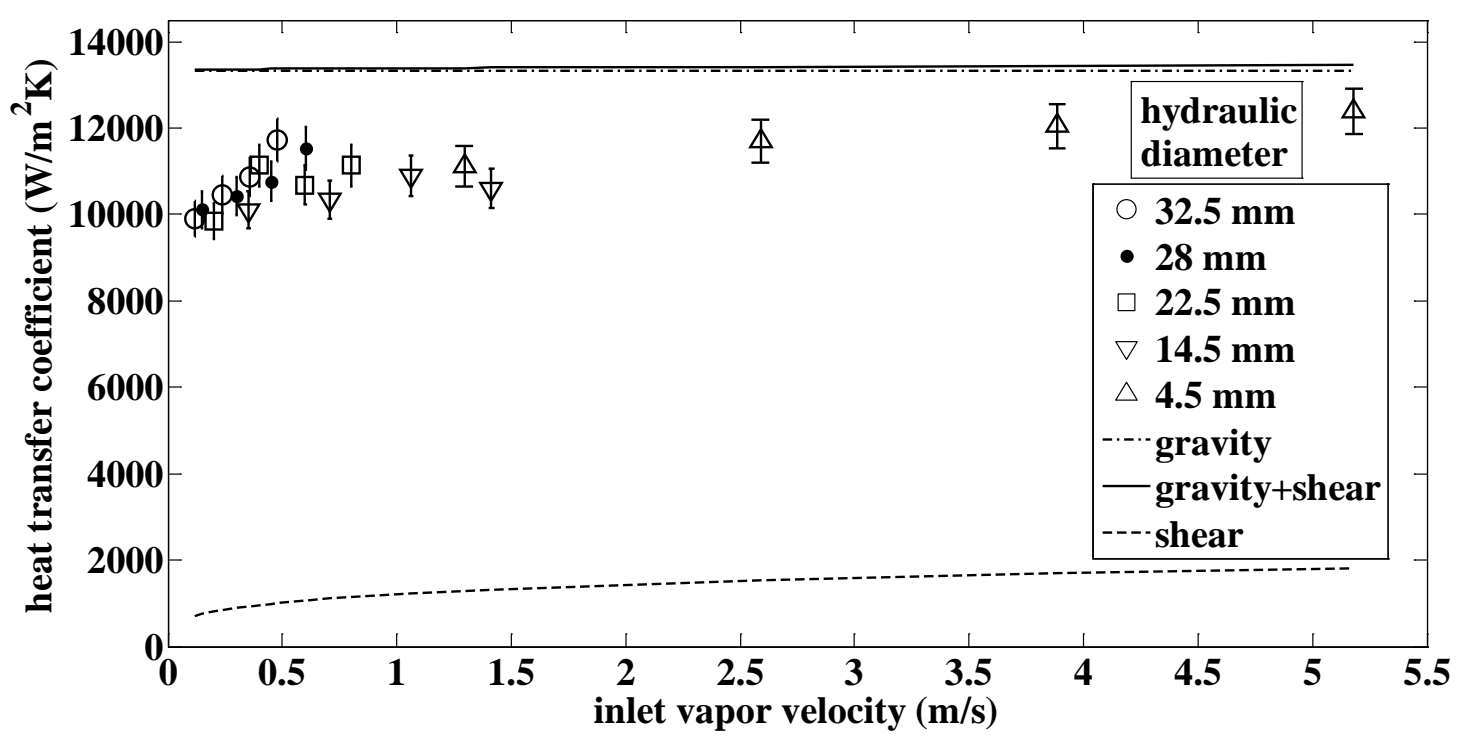

Figure 5. Comparison of theoretical heat transfer analyses and the experiments for completely hydrophilic surface. 


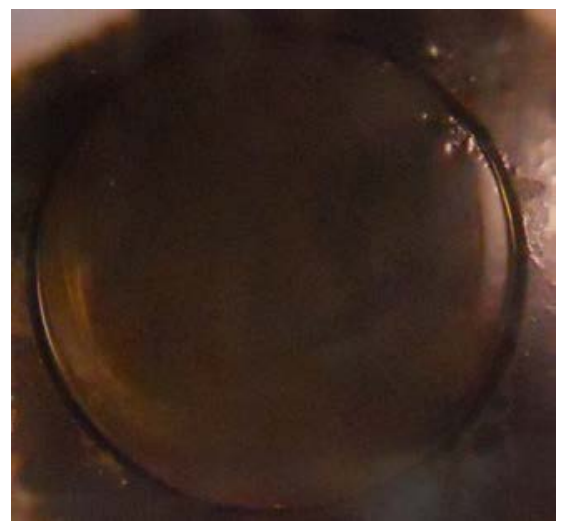

Figure 6. A film is seen to cover the entire hydrophilic surface.

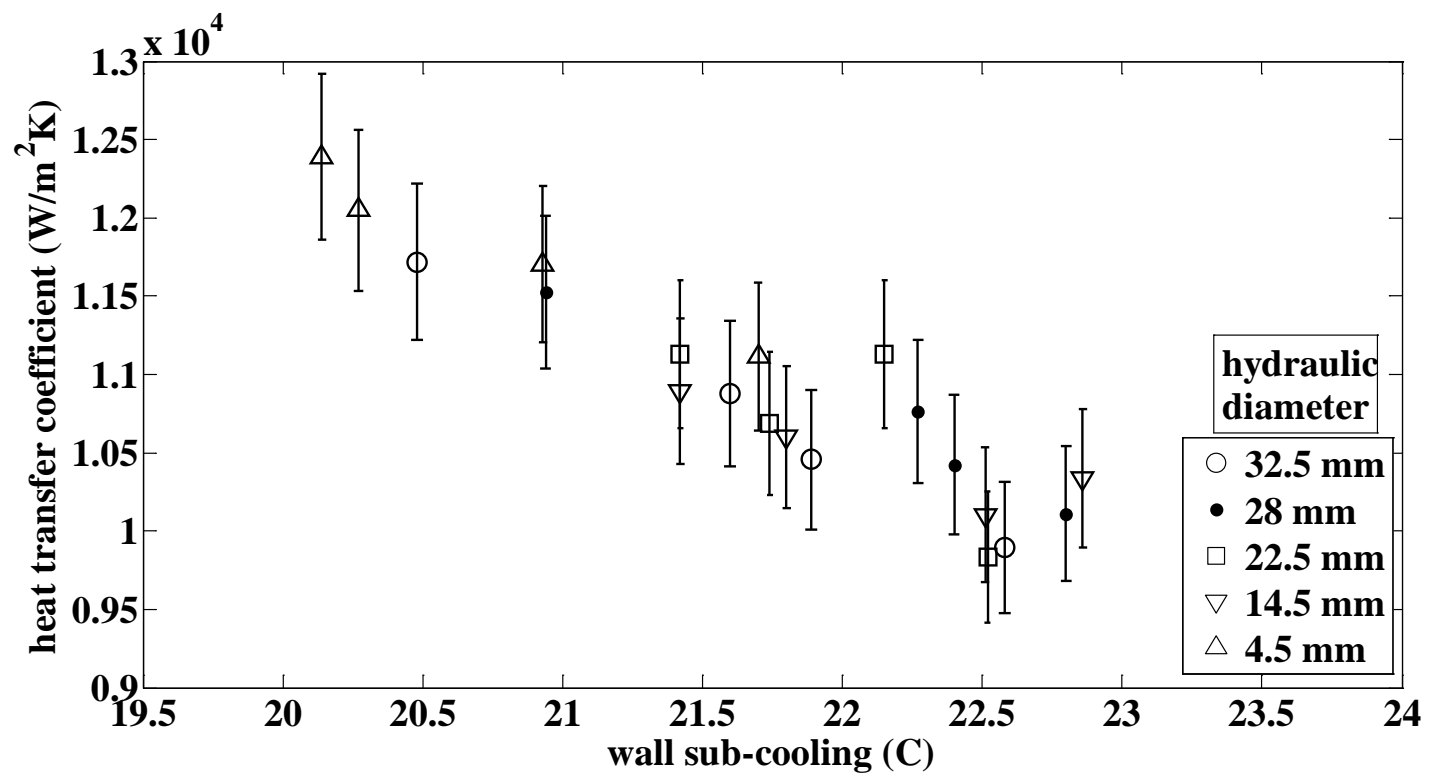

Figure 7. Variation of heat transfer coefficient with wall sub-cooling for completely hydrophilic surface. 
Condensation Heat Transfer on Patterned Surfaces

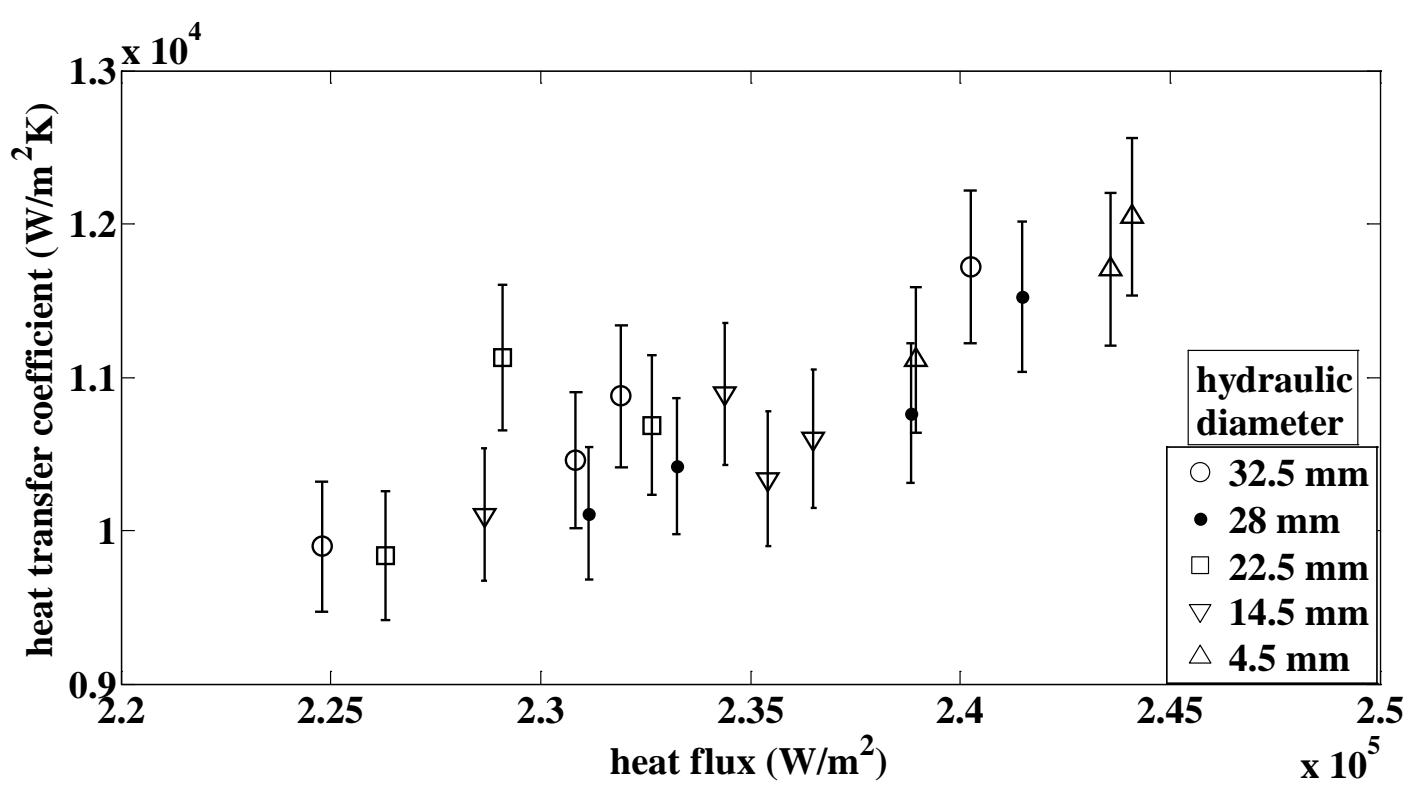

Figure 8. Variation of heat transfer coefficient with heat flux for completely hydrophilic surface.

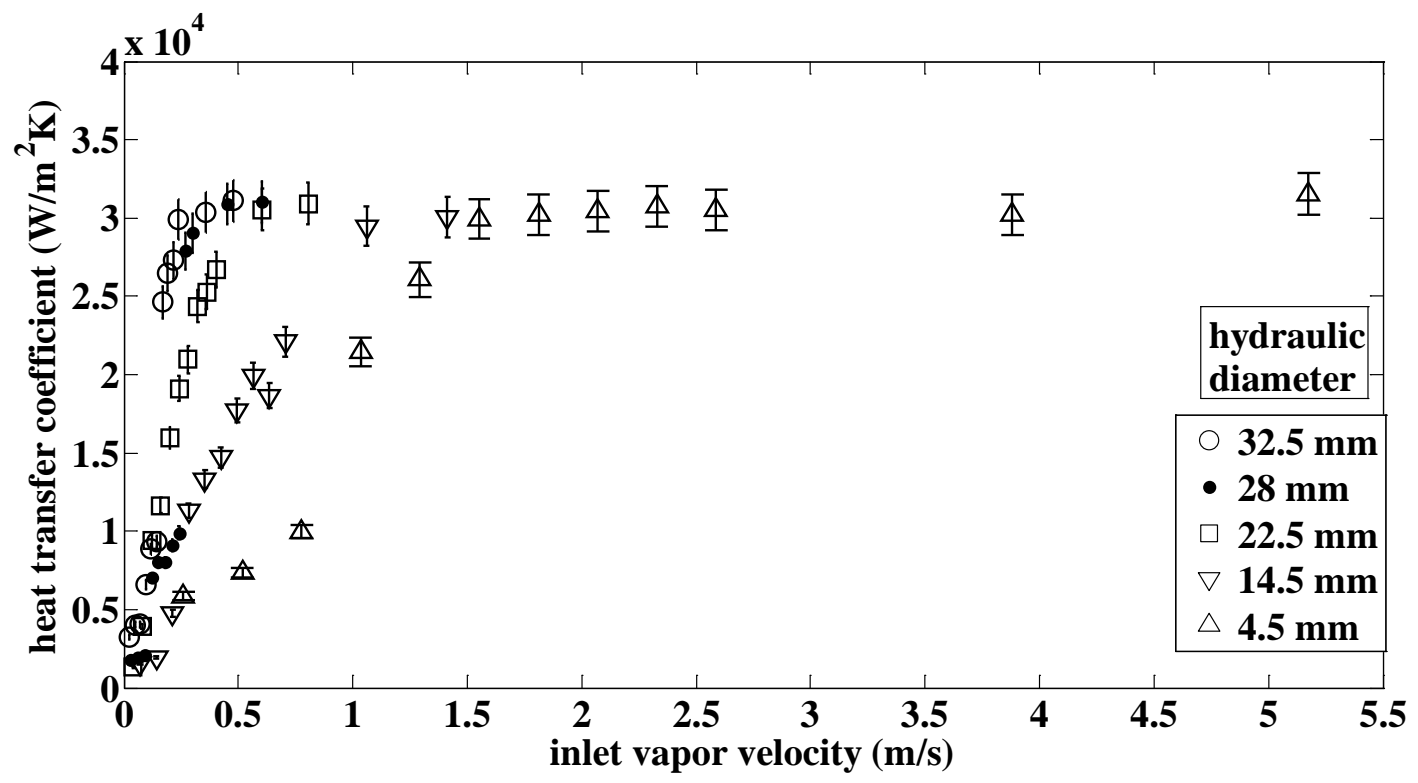

Figure 9. Variation of heat transfer coefficient with inlet vapor velocity for completely hydrophobic surface. 
Condensation Heat Transfer on Patterned Surfaces

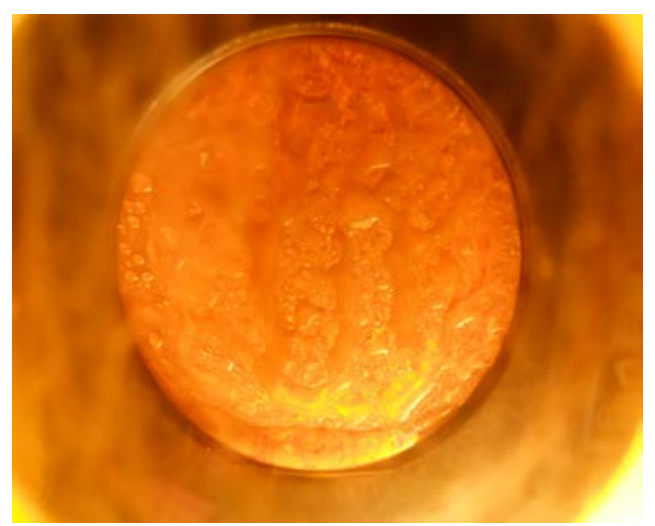

Figure 10. A combination of $D W C$ and $F W C$ is seen on the condensation surface. Steady streams or rivulets are also seen toward the geometric center of the condensation surface. 
Condensation Heat Transfer on Patterned Surfaces

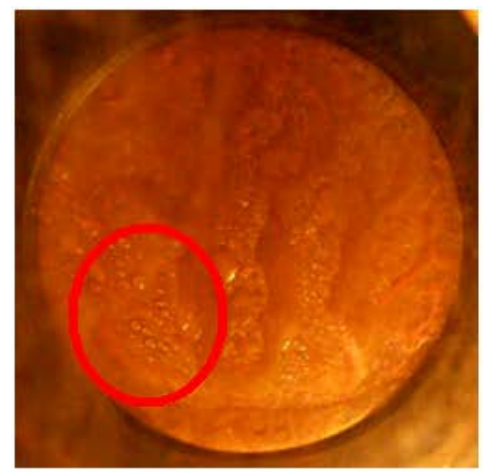

(a) $\mathrm{t}=0 \mathrm{~s}$

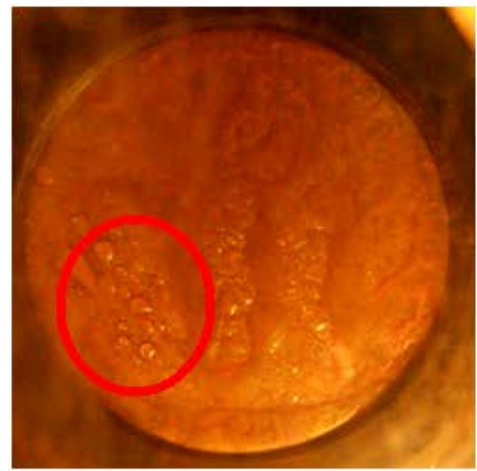

(b) $\mathrm{t}=1 \mathrm{~s}$

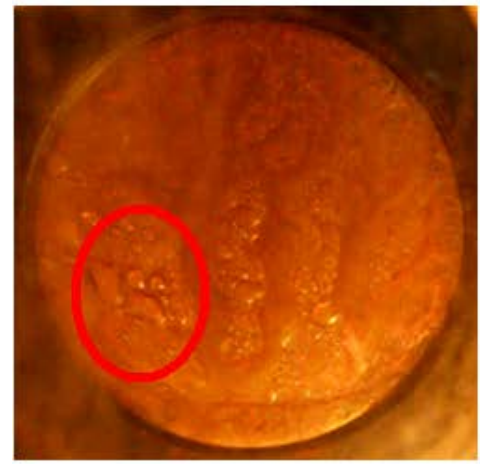

(c) $t=2 s$

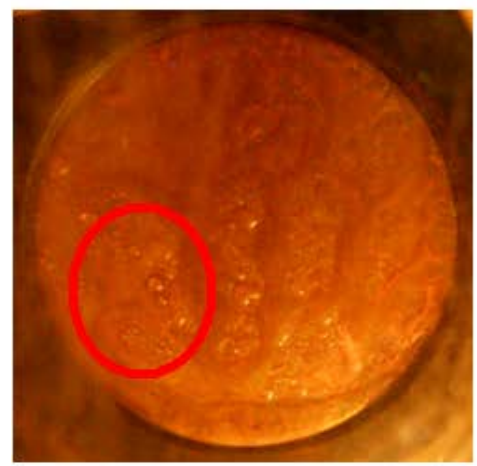

(d) $\mathrm{t}=3 \mathrm{~s}$

Figure 11. Droplets are seen to (a) nucleate, (b) grow, (c) coalesce, and (d) depart on the peripheral regions of the completely hydrophobic condensation surface, while rivulets are seen on the central region 


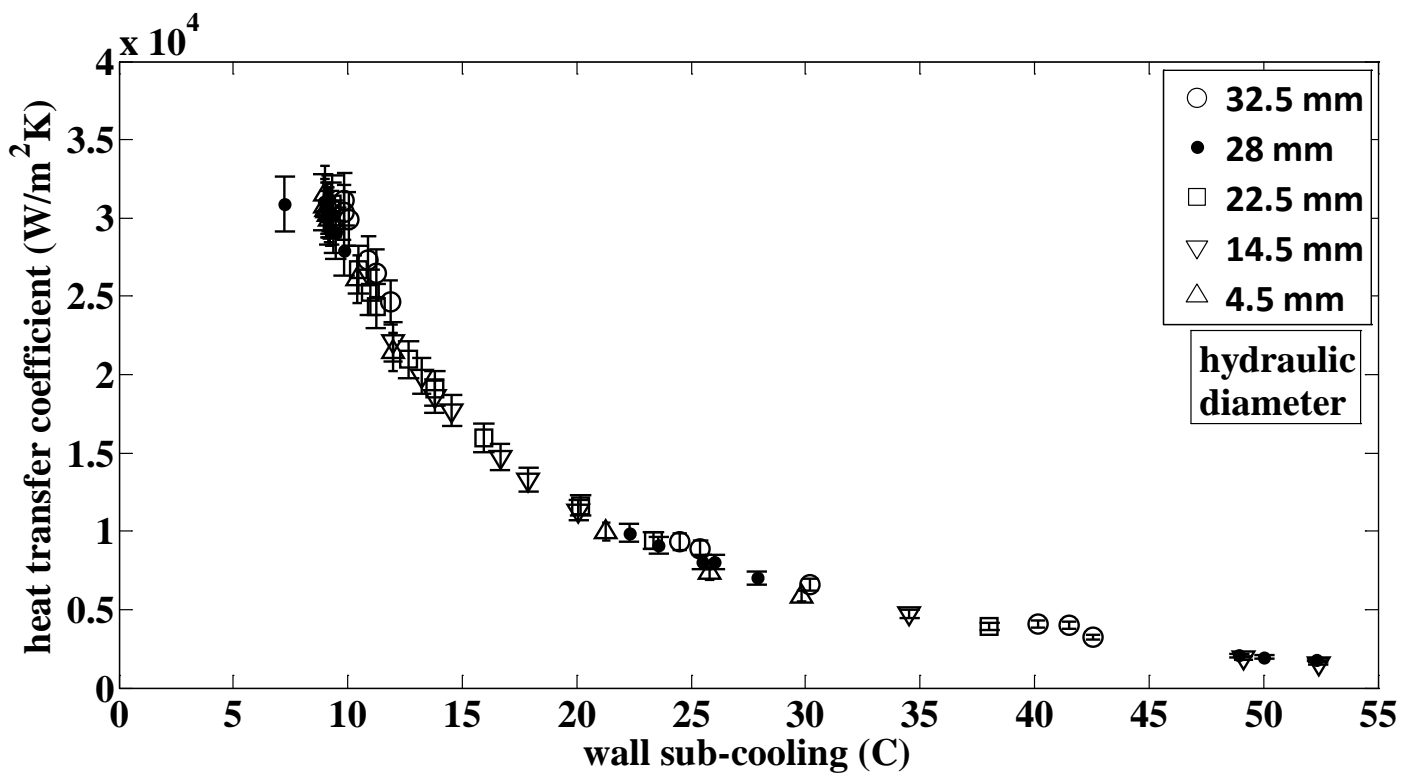

Figure 12. Variation of heat transfer coefficient with wall sub-cooling for completely hydrophobic surface.

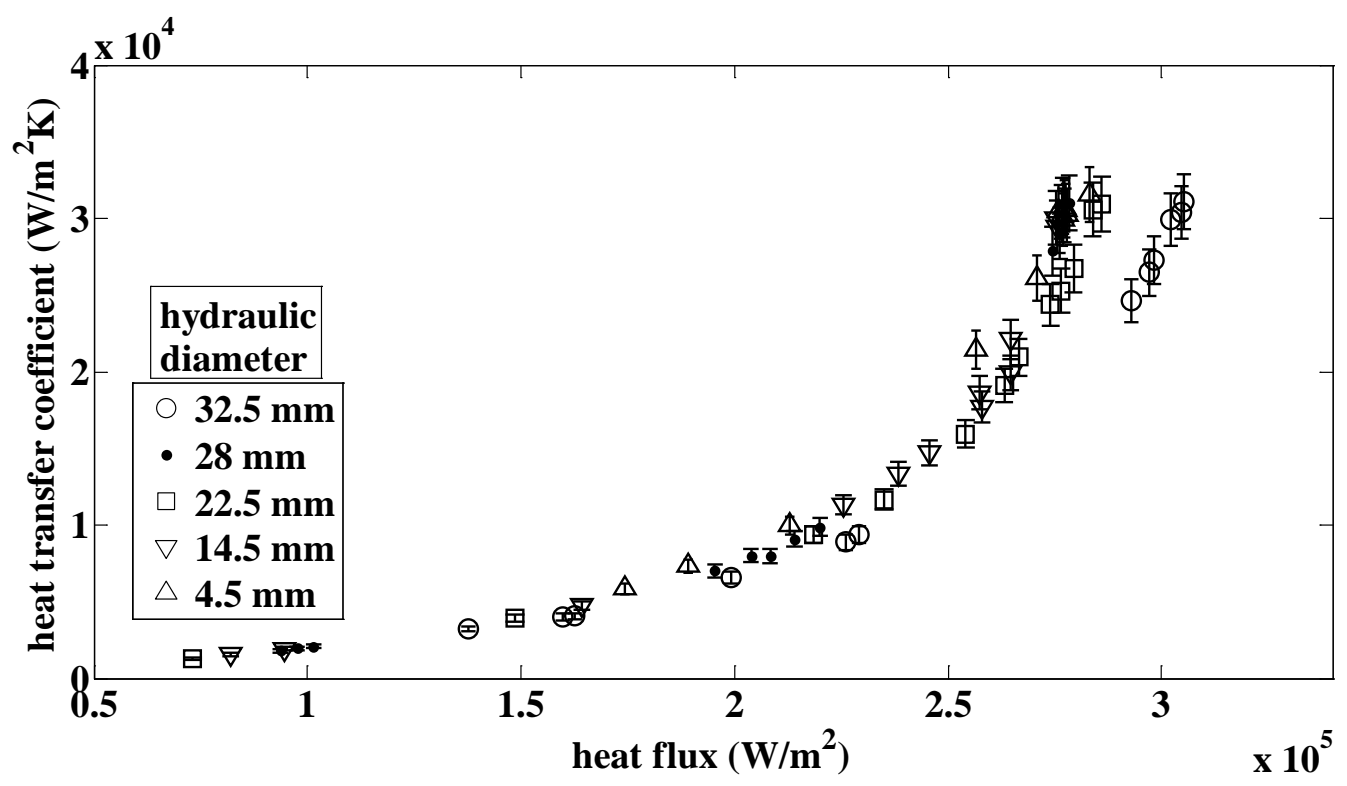

Figure 13. Variation of heat transfer coefficient with heat flux for completely hydrophobic surface. 
Condensation Heat Transfer on Patterned Surfaces

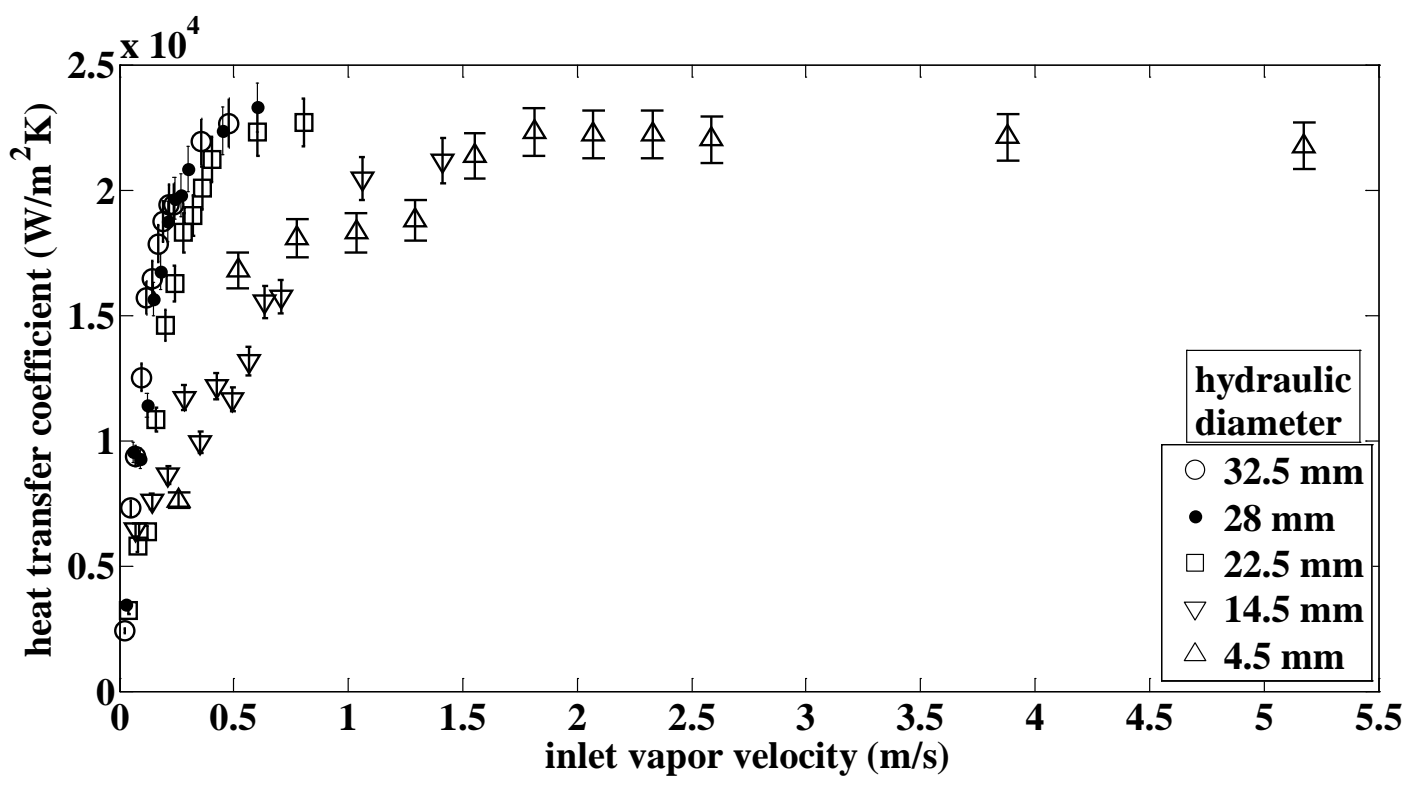

Figure 14. Variation of heat transfer coefficient with inlet vapor velocity for completely for patterned surface.

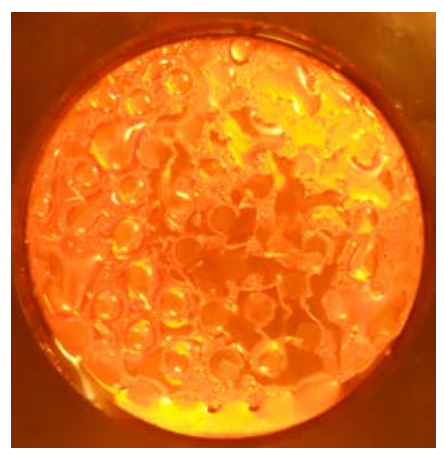

Figure 15. Bigger droplets are seen over the hydrophilic regions when compared to that over hydrophobic region. 
Condensation Heat Transfer on Patterned Surfaces

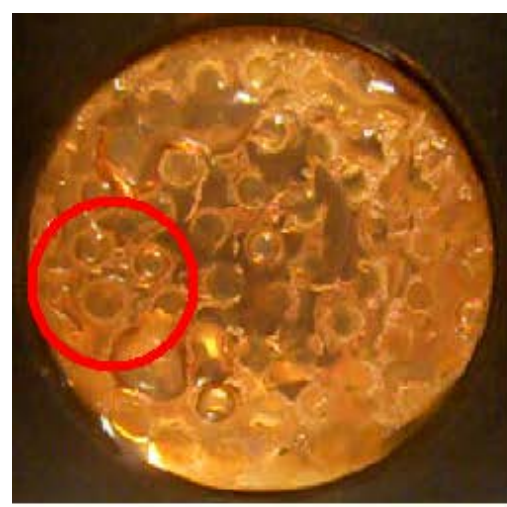

(a) $\mathrm{t}=0 \mathrm{~s}$

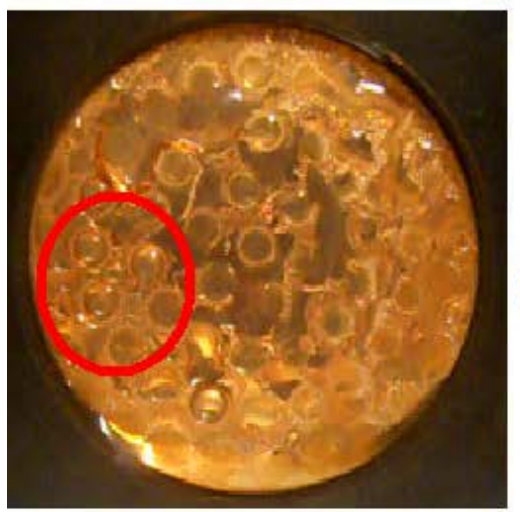

(b) $\mathrm{t}=2 \mathrm{~s}$

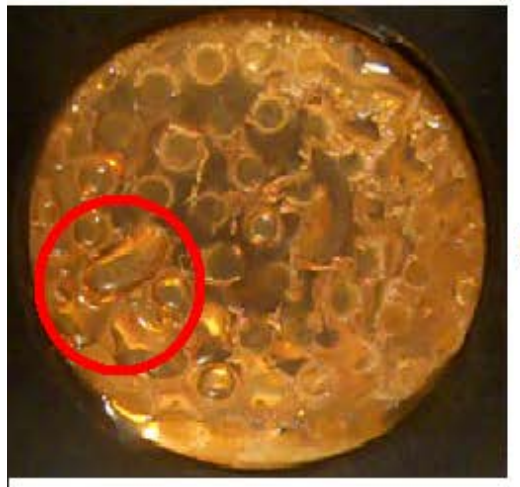

(c) $\mathrm{t}=9 \mathrm{~s}$

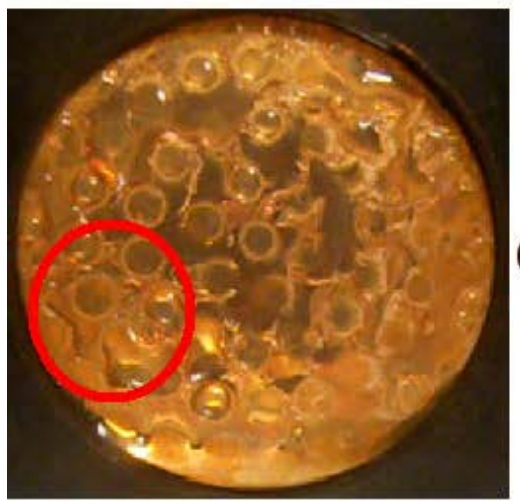

(d) $\mathrm{t}=12 \mathrm{~s}$

Figure 16. Droplets (a) nucleate, (b) grow, (c) coalesce and (d) depart on the patterned surface with hydrophilic island diameter $\approx 1.50 \mathrm{~mm}$ 


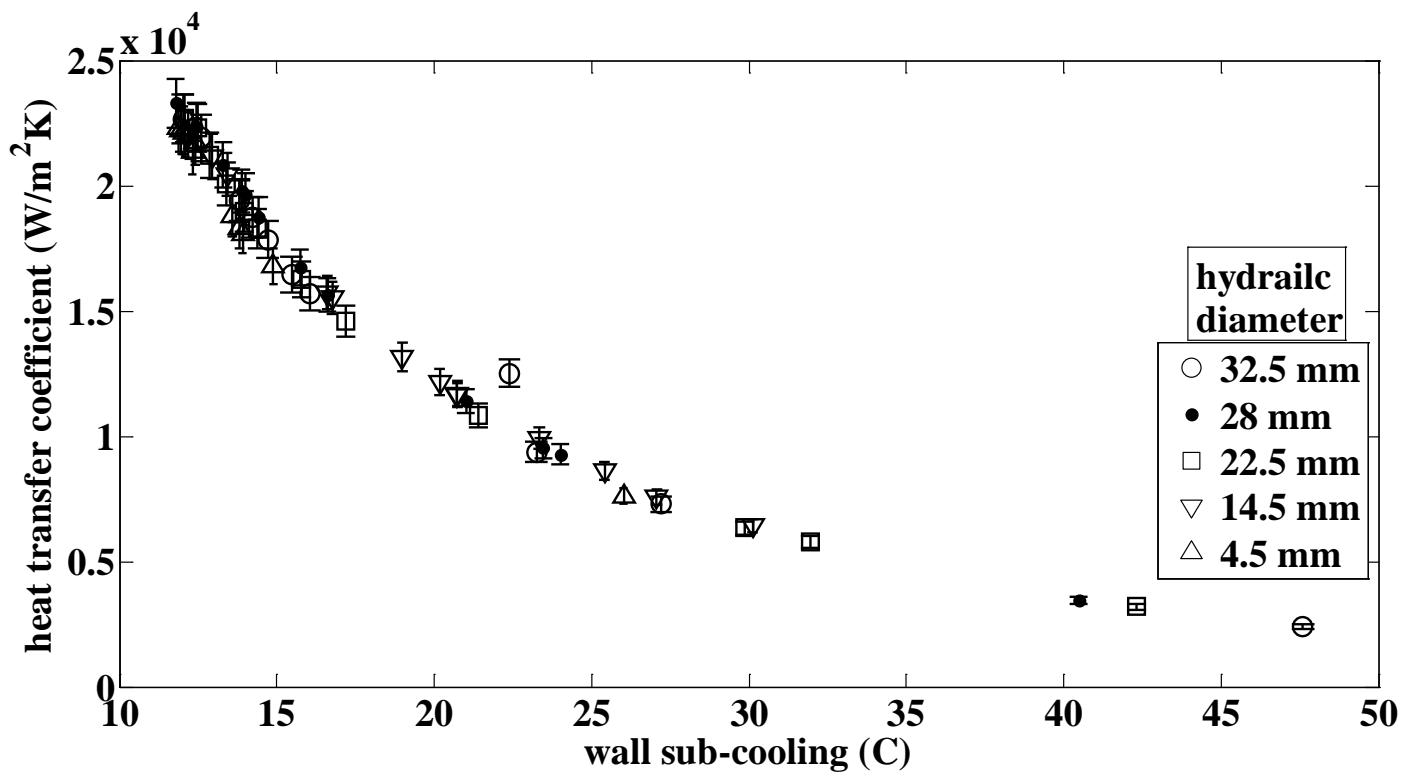

Figure 17. Variation of heat transfer coefficient with wall sub-cooling for completely for patterned surface.

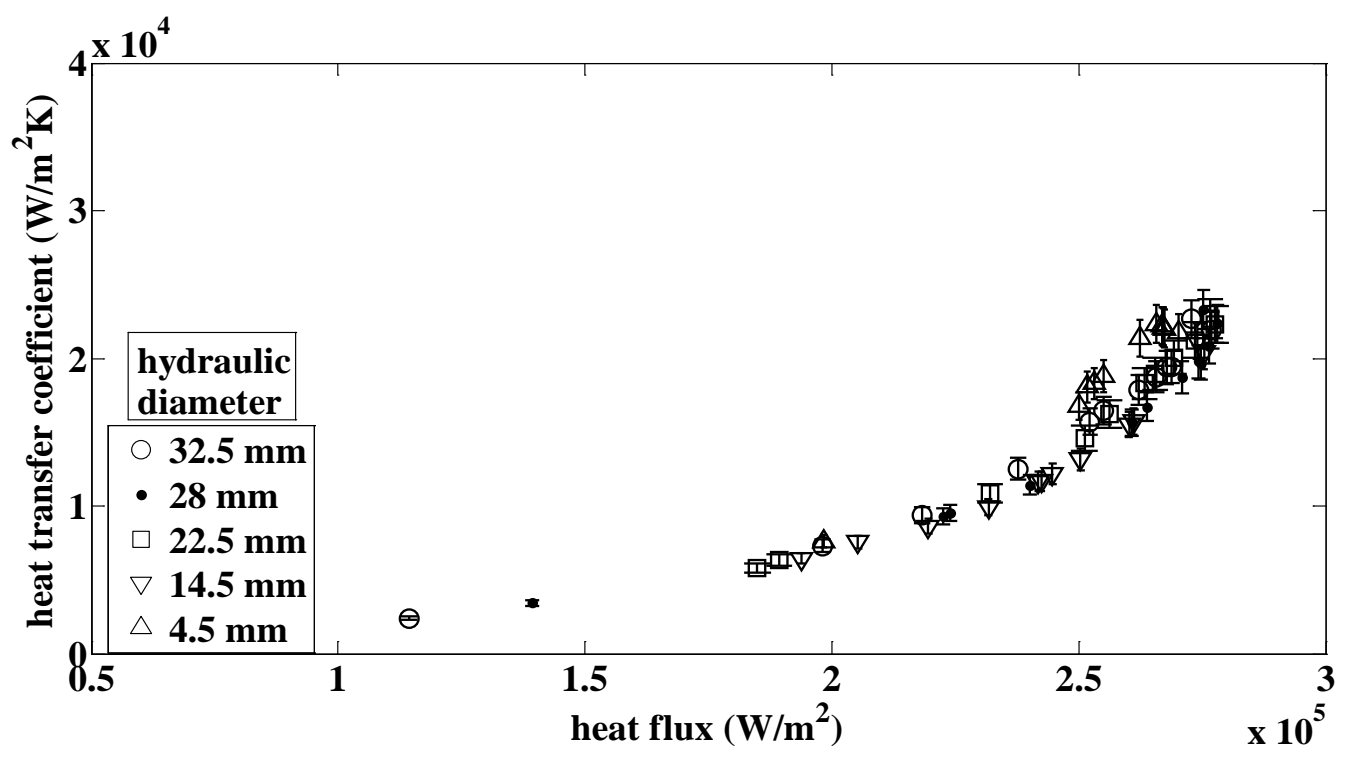

Figure 18. Variation of heat transfer coefficient with heat flux for completely for patterned surface. 


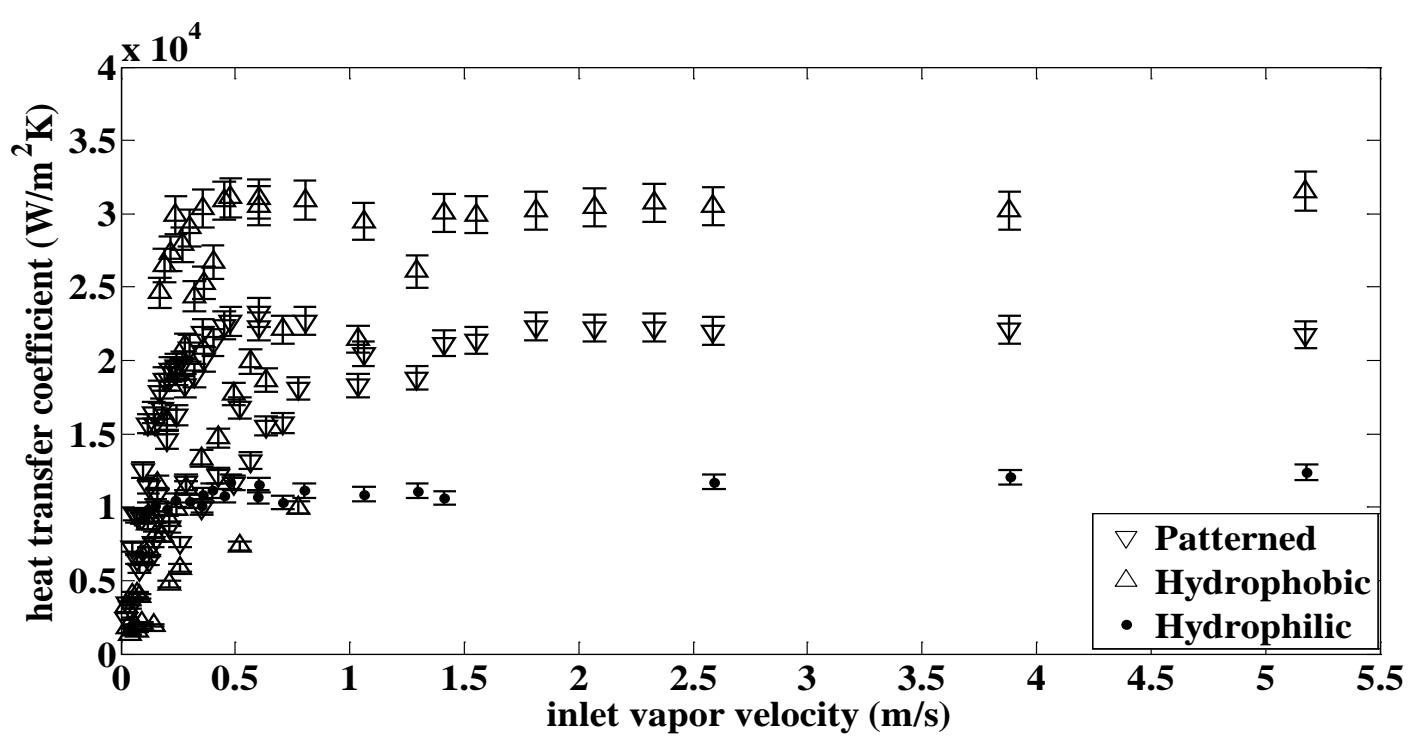

Figure 19. Comparison of the variation of heat transfer coefficient with inlet vapor velocity for completely hydrophobic, completely hydrophilic and patterned surface.

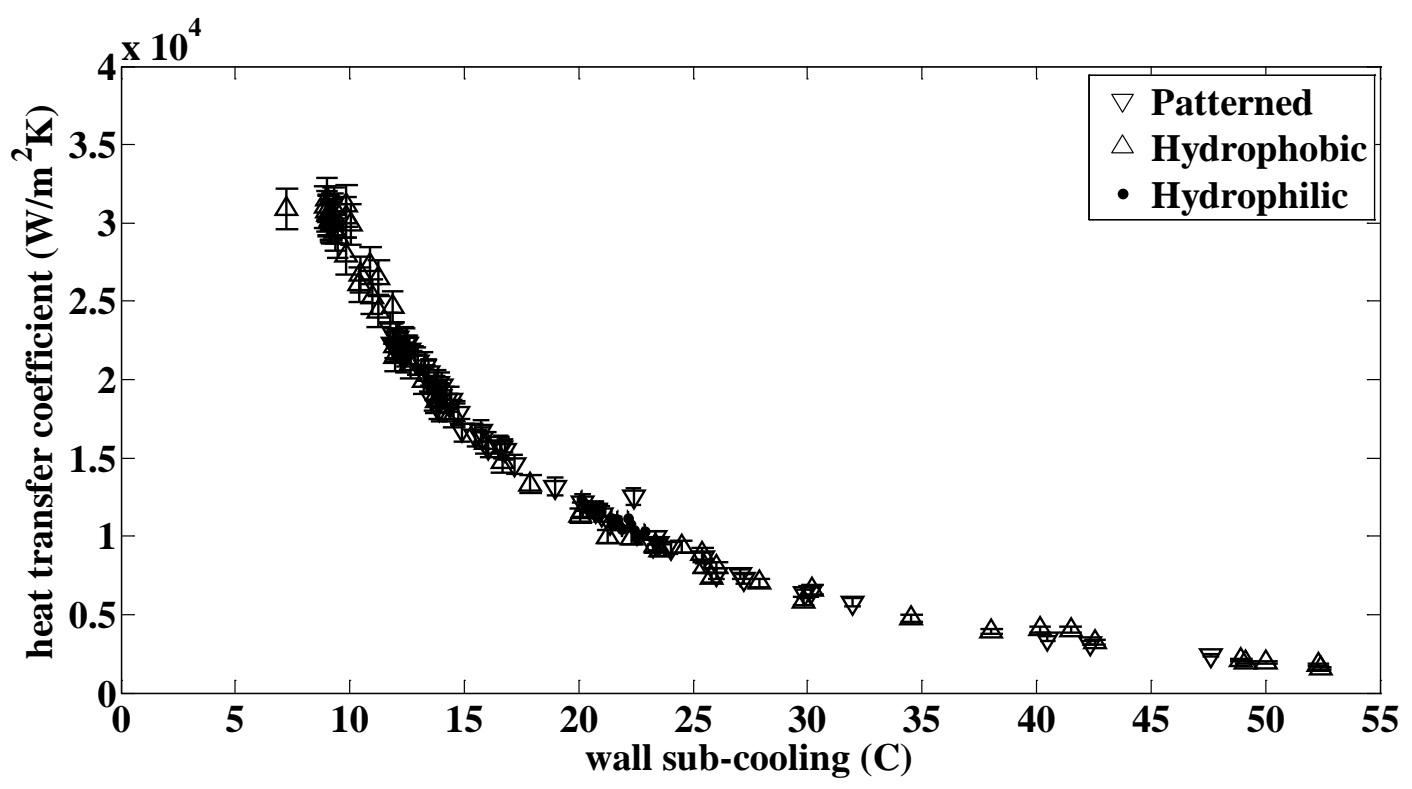

Figure 20. Comparison of the variation of heat transfer coefficient with wall sub-cooling for completely hydrophobic, completely hydrophilic and patterned surface. 


\section{Condensation Heat Transfer on Patterned Surfaces}

(C) 2013. This manuscript version is made available under the CC-BY-NC-ND 4.0 license

http://creativecommons.org/licenses/by-nc-nd/4.0/ 